\title{
Prediction of California Bearing Ratio from Consistency and Compaction Characteristics of Fine-grained Soils
}

\author{
Kamal Ahmed Rashed ${ }^{1}$, Nihad Bahaaldeen Salih ${ }^{2}$, Tavag Aram Abdalla ${ }^{3^{*}}$
}

\section{Authors affiliations: \\ 1) Department of Civil Engineering, College of Engineering, University of Sulaimani, Sulaimaniyah-Iraq, kamal.rashed@univsul.edu.iq}

\section{2) Department of Water} Resources Engineering, College of Engineering, University of Sulaimani, Sulaimaniyah-Iraq, nihad.salih@univsul.edu.iq

3*) Department of Civil Engineering, College of Engineering, University of Sulaimani, Sulaimaniyah-Iraq, tavga.abdalla@univsul.edu.iq

\section{Paper History:}

Received: $10^{\text {th }}$ July 2021

Revised: $15^{\text {th }}$ Sep. 2021

Accepted: 13 ${ }^{\text {th }}$ Oct. 2021

\begin{abstract}
Soil's characteristics are essential for the successful design of projects such as airports runway and flexible pavement. CBR (California Bering Ratio) is one of the significant soil characteristics for highways and airports projects. Thus, the CBR property can be used to determine the subgrade reaction of soil through correlations. Many of the soil geotechnical parameters such as compaction characteristics (Maximum Dry Density, MDD; Optimum Moisture Content, OMC), and consistency parameters (Liquid Limit, LL; Plastic Limit, PL; Plasticity Index, PI) can be in charge of changes that happen in soil CBR value. Soaked and/or non-soaked conditions of soils also affect CBR value. Hence, testing soils in a laboratory for CBR calculation is timeconsuming that needs notable effort. Therefore, this study aims to generate some useful correlations for soil's CBR with compaction and consistency parameters for 85 samples of fine-grained soils. The study trials were applied on natural soil samples of various places in Sulaimani Governorate, Northern Iraq. Statistical analysis has been carried out by using SPSS software (Version 28). Soaked CBR is counted, which is important for conditions such as rural roads that remain prone to water for few days. Based on the statistical analysis, there is a significant correlation between LL, PL, PI, MDD, and OMC with CBR as the dependent variable as a single variable equation with $\mathrm{R}^{2}$ of 0.7673 , $0.5423,0.5192,0.6489$, and 0.51 , respectively. In addition, the highest value of $\mathrm{R}^{2}$ correlation was obtained between $\mathrm{CBR}$ value with consistency and compaction properties as a multiple regression equation with $\mathrm{R}^{2}$ of 0.82 . The obtained equations for correlation purposes are successfully achieved and can be used, notably, to estimate CBR value.
\end{abstract}

Keywords: California Bearing Ratio, Geotechnical Properties, Correlation, Fine-grained Soils.

$$
\begin{aligned}
& \text { التنبؤ بنسبة تحمل كاليفورنيا من خصائص الانساق والضغط للتربة ذات الحبيبات } \\
& \text { الدقيقة } \\
& \text { كمال احمد رشيد، نهاد بهاءالدين صالح، نافكه آرام عبدالله }
\end{aligned}
$$

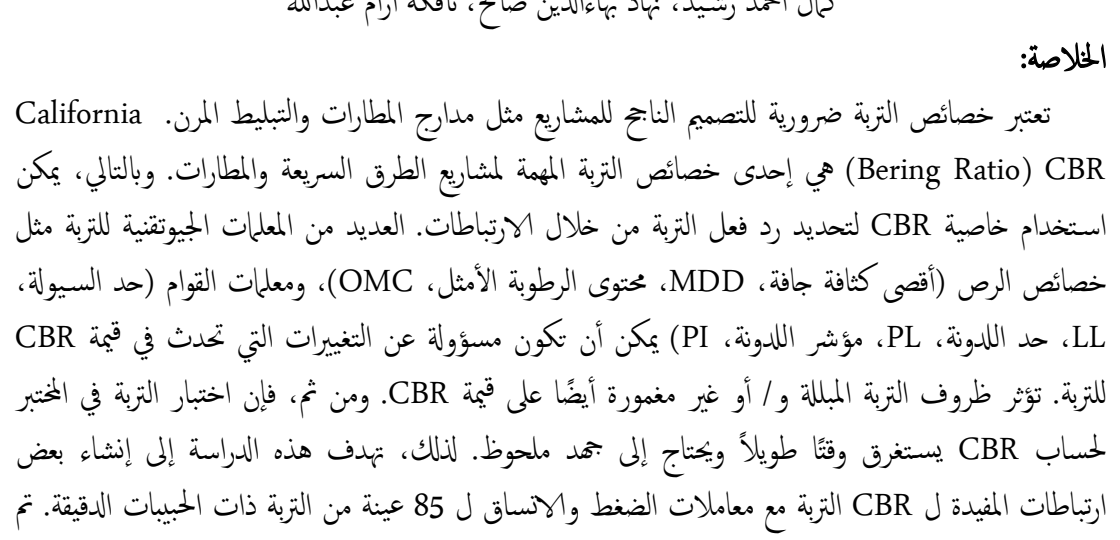




\section{Introduction}

A stable foundation is essential for successful sustainable projects such as buildings, roads and highways, dams, and other projects that utilize great earthwork. So, having reliable approaches are essential to obtain the required engineering properties for such projects. For the conduction of the current study, natural samples of soil of Sulaimani Governorate, Northern Iraq were gathered. Although the laboratory calculation of CBR is consuming of long time, tedious, and expensive, multiple tests need to be performed through the distance of pavement to obtain proper insight into the strength of the subgrade. This issue delays projects and increases their cost. Therefore, CBR values need to be predicted on the basis of simply determined and basic soil properties to save time and money.

Finding some empirical relationships to predict Soil's CBR property by utilizing the soil's consistency and compaction parameters is the aim of the current study. Most of the used soil data were obtained from Sulaimani Central laboratories for testing materials. Many researchers have studied soil CBR, for instant, Danistan and Vipulanandan [9], Nugroho et al. [18], Maghdi and Zumrawi [15] studied clayey soils CBR property (soaked and non-soaked) as a function of some soils index parameters, namely: PI, natural moisture content, dry density, and void ratio. Their finding yielded in a good relation for CBR and PI.

The prediction of CBR of fine-grained soil as a function of Soil's consistency properties was considered in many studies such as Talukdar [29], and Saklecha et al. [25], Roy [23], Bassey et al. [7], Farias et al. [10], and Torgano et al. [35], their results reveal that correlations of CBR with LL, PL, and PI as a single variable were concluded to be relatively negative in the prediction of the real CBR value cannot be from those limits. However, good correlations for prediction of CBR value from LL, PL, PI, OMC, and MDD with as a single variable equation were achieved by Kumar et al. [13], Prashanth et al. [21], Gudeta and Patel [11], Mishra and Tegar [16], Priya et al. [31], and Katte et al. [12]. Moreover, various indx parameters such as specific gravity $(\mathrm{G})$, coefficient of uniformity $(\mathrm{Cu})$, coefficient of curvature (Cc), liquid limit (LL), plastic limit (PL), plasticity index (PI), optimum moisture content (OMC) and maximum dry density (MDD) for alluvial soil were correlated with CBR in the study of Alam et al. [1]. The study considered both soaked and unsoaked CBR values as a function of those index properties by utilizing Genetic Expression Programming (GEP), artificial neural network
(ANN), and kriging methods. The study outcomes clearly reveal that for prediction of both soaked and un-soaked CBR values by using soil's index properties, the GEP, ANN, and kriging methods can be effectively employed. Singh [27] Utilized 16 natural soil samples from the Nagaon district of Assam for the purpose of soil properties correlation. CBR property was correlated with MDD, OMC, LL, PL, and PI. CBR value correlation with the soil index properties was conducted by multiple linear regression analysis (MLRA).

Patel and Desai [20] developed correlations between various soils' geotechnical properties such as MDD, OMC and CBR in soaked conditions. So, from multiple variable regression analysis, empirical correlations were developed, which were gained as results of soil's laboratory testing collected from different places in Gujarat, India. In addition, Muley and Jain [17] studied the poor soil's CBR after mixed with a stone dust. The study performed to obtain a correlation to predict the soil CBR. Moreover on correlation purposes, MLRA models were developed to determine correlations between CBR with soil index properties [6, 8, 21, 26, 27, 28 and 33].

This study aims to achieve valuable correlations between soil's CBR and other geotechnical properties, namely consistency and compaction parameters of locally available fine particles soils in Sulaimani Governorate, Northern Iraq. Hence, the allocated objectives of current work are:

Development of equations for correlation purpose for soil's CBR with consistency and compaction parameters

To compare the predicted CBR values (by developed regression equation) with the laboratorydetermined CBR values.

To find the linear correlation equation which is use for find necessary properties of sub-grade soils for other place.

\section{Materials and Methods}

Eighty-five natural samples of soil were taken from various selected parts of Sulaimani Governorate. Many Laboratory experiments were carried out such as those to obtain LL, PL, compaction characteristics and CBR. All these conducted experiments were followed the instructions for each test from the global ASTM specifications (Table 1). Both of linear regression analysis (simple) and MLRA are chosen and utilized to gain the required equation for prediction of CBR (soaked) from consistency and compaction parameters. So, for MLRA conduction, the values of 
soil's CBR considered as a dependent variable, while PI, PL, LL, OMC and MDD as the independent variables. Coefficient of determination $\left(\mathrm{R}^{2}\right)$ and root minimum square error (RMSE) are used as evaluation criteria to check the calculated empirical correlations between compaction characteristics versus index properties.

Table (1): Soil test standards used for testing the soil samples in this study.

\begin{tabular}{|c|c|}
\hline Soil Test & Specification \\
\hline Atterberg Limits & {$[3]$} \\
\hline $\begin{array}{c}\text { Modified Proctor } \\
\text { Compaction }\end{array}$ & {$[4]$} \\
\hline CBR & {$[5]$} \\
\hline
\end{tabular}

\section{Results and Discussions}

The studied soil samples of Sulaimaniyah governorate were found to be clayey or silty soil with low to high plasticity, which can be defined as low plasticity soil (CL) considering the Unified Soil Classification System (USCS) ASTM D-2487 [2]. Table 2 gives a list of the obtained statistical parameters and database results from the experimental work performed on 85 soil samples from Sulaimani City.

Table 2: Statistical parameters for the calculated geotechnical characteristics.

\begin{tabular}{|c|c|c|c|c|c|c|}
\hline & \multicolumn{2}{|c|}{ Atterberg Limits } & \multicolumn{2}{c|}{ Compaction } & CBR \\
\cline { 2 - 6 } & LL & PL & PI & MDD & OMC & value \\
\hline $\begin{array}{c}\text { Maximum } \\
\text { value }\end{array}$ & 49 & 34 & 19 & 2.122 & 21.2 & 17 \\
\hline $\begin{array}{c}\text { Minimum } \\
\text { Value }\end{array}$ & 24 & 15 & 2 & 1.625 & 7.2 & 1.4 \\
\hline Range & 25 & 19 & 17 & 0.497 & 14 & 15.6 \\
\hline Mean & 39.76 & 26.96 & 12.73 & 1.79 & 15.5 & 4.82 \\
\hline Median & 42 & 27 & 14 & 1.778 & 16 & 3.3 \\
\hline Mode & 44 & 30 & 14 & 1.794 & 15.4 & 3 \\
\hline $\begin{array}{c}\text { Standard } \\
\text { dev. }\end{array}$ & 6.41 & 4.473 & 3.473 & 0.105 & 3.12 & 3.53 \\
\hline Units & $\%$ & $\%$ & $\%$ & $\mathrm{gm} / \mathrm{cm}^{3}$ & $\%$ & $\%$ \\
\hline
\end{tabular}

\subsection{Linear Regression Analysis (Simple)}

Figure 1 represents a graph, shows the soaked CBR significantly correlated with the liquid limit as a single variable. This is noticed from the achieved values of $\mathrm{R}^{2}$ and RMSE, which were 0.767 and 1.69 respectively. Figure 1 clearly indicates that the higher LL caused a lower CBR. A higher LL value means that the clay fractions content is notable and active for water absorption naturally, which may cause the load-bearing capability of the soil to decrease. Therefore, for smaller LL, higher CBR was obtained. The mathematical relation between the two parameters is shown in Equation (1). Similarly, the mentioned relation are also reported in several studies, however current study's results are higher than the results of developed relations by Talukdar [28], Saklecha et al. [25], Roy [23], Farias et al. [10], Bassey et al. [7], and Torgano et al. [30]. In those studies, it is concluded that the CBR and liquid limit correlations are relatively negative, in addition to prediction of the real CBR value, the limit cannot be utilized. In contrast, the result of Prashanth et al. [21], and Mishra and Tegar [16] were higher compare with the result of this study. Those studies outcomes were proved by depending on mathematical modeling through using practically-determined CBR value. Moreover, the considered soils in the current study have low to medium plasticity characteristics representing the real field states of those soils available in general in Sulaimani Governorate, Northern Iraq. Therefore, the achieved good correlations with CBR means that those obtained equations can be successfully working for CBR values determination for low to medium plasticity soils.

CBR $($ soaked $)=-0.4829 \mathrm{LL}+24.018$.

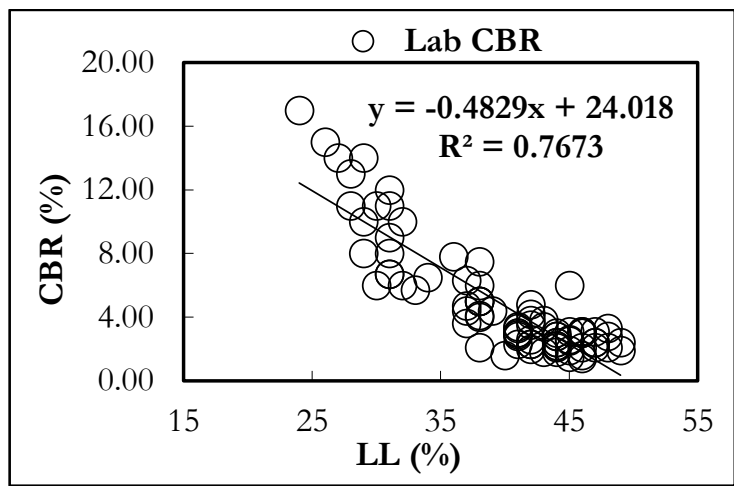

Figure 1: Relationship of CBR with LL of the soil samples.

The relation between $\mathrm{CBR}$ and $\mathrm{PL}$ is also considered and given in Figure 2, which can be represented by the following equation with coefficient of determination $\left(\mathrm{R}^{2}\right)$ and the lower value of RMSE equal to 0.58423 and 2.37 , respectively. The mathematical relation between the two parameters is shown in Equation (2). Clay mineral types and percent may be responsible for this type of relationship. The testing procedure and methods may affect the accuracy of the collected data and correlation success. Other factors, such as particle size and shapes, distribution of voids and availability of various minerals, may play a notable role. This study result is larger than the result obtained in the study of Roy [23], Bassey et al. [7], Priya et al. [31], and Torgano et al. [30], negative correlations between plasticity index and CBR was observed. The present study outcome is less than the achieved result by Prashanth et al. [21], Mishra and Tegar [16], which were achieved $\mathrm{R}^{2}$ values of 0.757 and 0.934 , respectively.

CBR $($ Soaked $)=-0.5815$ PL +20.497 


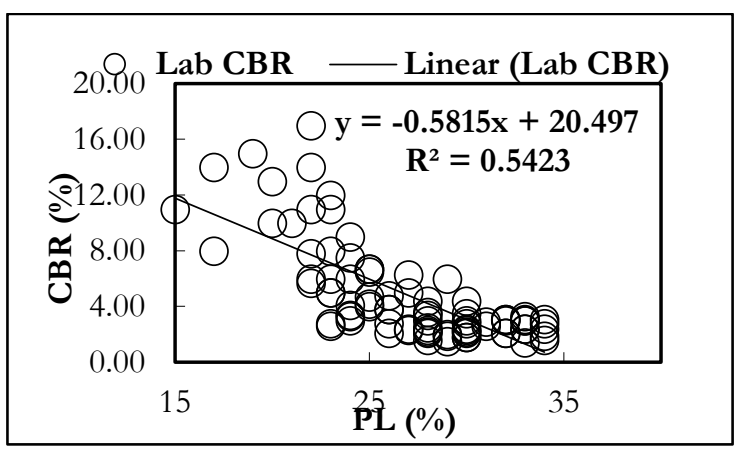

Figure 2: The soil samples CBR and PL relationship.

The variation of PI with CBR values as a single variable shown in Figure 3. The obtained correlation is weak and CBR value is not proposed to be computed from PI. This weak relation may be due to clay mineral types and percent. The testing procedure and methods may affect the accuracy of the collected data and the correlation success. The availability of various types' minerals may also play a notable role. From Figure 3 it has been observed that CBR value decreases with increase in the value of plasticity index of soil. $\mathrm{R}^{2}$ values for Eq. 3 (see Table 3 for statistical parameters) was 0.5192 , which is above $50 \%$ implies that a notable correlation between independent and dependent variables in this study. This achievement agrees with the achieved results in the studies of Prashanth et al. [21], Mishra and Tegar [16], Gudeta and Patel [11], and Priya et al. [31]. However, several studies' outcomes showed that the relationship by utilizing plasticity index parameter cannot be accurately used to predict the values of soaked CBR (Roy [23], Bassey et al. [7], and Torgano et al. [30]).

$\mathrm{CBR}($ Soaked $)=-0.7331 \mathrm{PI}+14.148$

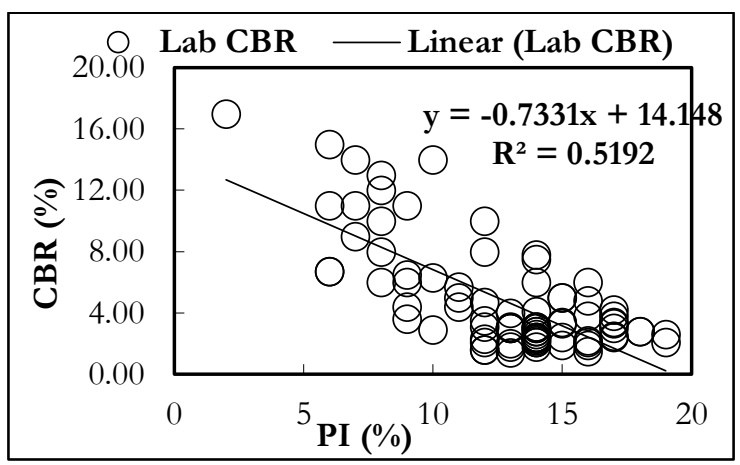

Figure 3: Relationship of the soil samples CBR and PI.

Reliable correlations between the soil samples CBR values and OMC were obtained and shown in Figure 4 and Equation (4). The correlation for this figure can be given by the linear equation with the value of $\mathrm{R}^{2}$ and RMSE equal to 0.51 and 2.46, respectively. The correlation between $\mathrm{CBR}$ and optimum moisture content was found significant (Figure 4) indicating that density influences the CBR value with the increase in the required $\mathrm{OMC}$ to obtain a reliable dry density. This indication is important for the foundations of construction projects; the soil sample provides a vast room for water absorption due to the available clay fractions in the soil sample, that way saving plenty of water in the diffuse layers of the soil sample. Hence, if the soil sample absorbs a large amount of water, then a high degree of particle lubrication and weak resistance to applied forces are possible, as noted in the correlation with CBR values. A negative correlation by several studies (Bassey et al. [7], Farias et al. [10], Torgano et al. [30] and Priya et al. [31]) was found for OMC and CBR values, and OMC cannot be utilized accurately in the prediction of the CBR value, which disagrees with the outcomes of the current study. The results of this study were compiled with the achievements of several studies such as Lakshmi et al. [14], Prashanth et al. [21], Roy [23], Mishra, and Tegar [16].

CBR $($ Soaked $)=-0.8079$ OMC $+17.338 \ldots$

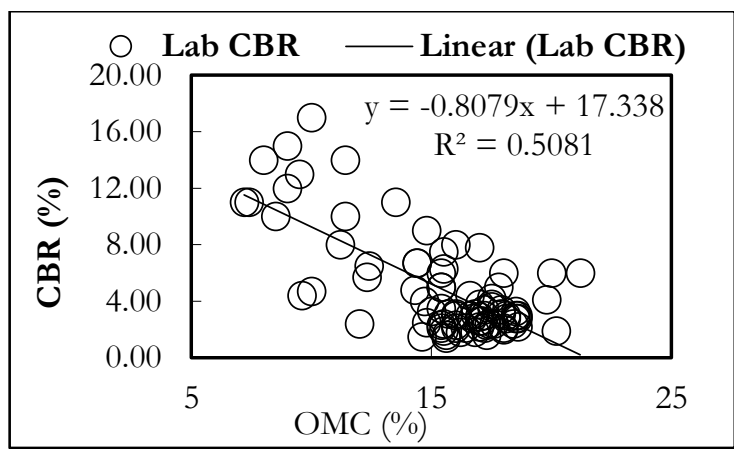

Figure 4: Relationship of CBR and OMC of the soil samples.

To focus on the required correlations for CBR values of the soil samples with the other geotechnical parameters, Figure 5 was prepared, which presents the correlated CBR values with MDD obtained from modified Proctor compaction test. From the figure and according to the good values of $\mathrm{R}^{2}$ and RMSE (add values of $\mathrm{R}^{2}$ and RSME), there is an acceptable correlation was obtained between MDD and CBR as a single variable equation. Logically, with the increase in MDD, the compacted sample is more capable of resisting the application of load, especially vertical ones. Thus, the resistance increases as the density increases. However, the value of $\mathrm{R}^{2}$ is not very high, which may be caused by some factors such as availability of clay minerals, their types and percent, testing procedure and methods, particle size and shapes, distribution of voids and availability of various minerals. Such factors may play a role in decreasing the accuracy of the obtained relationship. The findings of several studies such as Lakshmi et al. [14], Roy [23], Prashanth et al. [21], Mishra and Tegar [16] are in line with the achieved relationship shown in Figure 5, and Equation 5 of the current study. While, the mentioned relationship disagrees with the achievements of other studies such as Bassey et al. [7], Farias, et al. [10], Torgano et al. [30], Priya et al. [31], which concluded that there is no correlation between MDD and CBR values.

CBR $($ Soaked $)=27.094 \mathrm{MDD}-43.714$ 


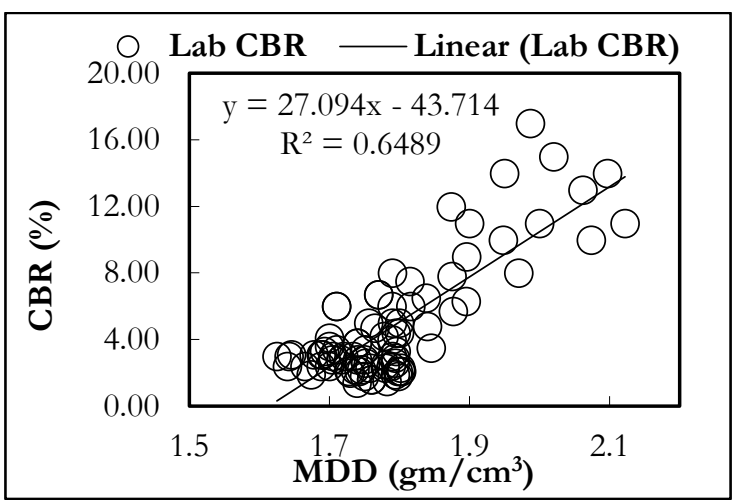

Figure 5: $\mathrm{CBR}$ values correlation with the soil samples MDD.

\subsection{Multiple regression analysis}

To achieve the more on the required objectives of current study, Tool Pak of Microsoft Excel was utilized for the data analysis purpose to gain a regression model (multiple).

Therefore, the following gained equation represents the successful outcome of the conducted analysis:

$\mathrm{CBR}=4.32-0.13662 \mathrm{PI}-0.01607 \mathrm{PL}+0.26614 \mathrm{LL}$ $-0.13504 \mathrm{OMC}+8.563 \mathrm{MDD}$

The coefficient of correlation $\left(\mathrm{R}^{2}\right)$ and RMSE for the above equation are 0.82 and 1.47 respectively. Hence, the equation effectively correlates the CBR value with other soil properties. In order to validate and check the successfulness of the obtained equation, Figure 6 was prepared. The determined CBR values obtained from the experiments carried out in a soil laboratory and the computed CBR values from Equation (6) were notably have similar behavior. A good correlation for CBR determination from five other geotechnical properties was obtained; thus, CBR cannot be predicted without testing. The testing accuracy seems to be significantly controlled. Thus, the soil type may work smoothly with the addition of water for those tests. The CBR values that calculated from the laboratory experiments are generally in agreement with the computed ones from the proposed Equation 6. However, a few points showed less agreement. This condition means that the CBR value can be determined from empirical equations successfully, which is the main goal of this study. Table 3 shows the summary of the developed empirical equations between consistency and compaction characteristics to predict the CBR value carried out in this study.

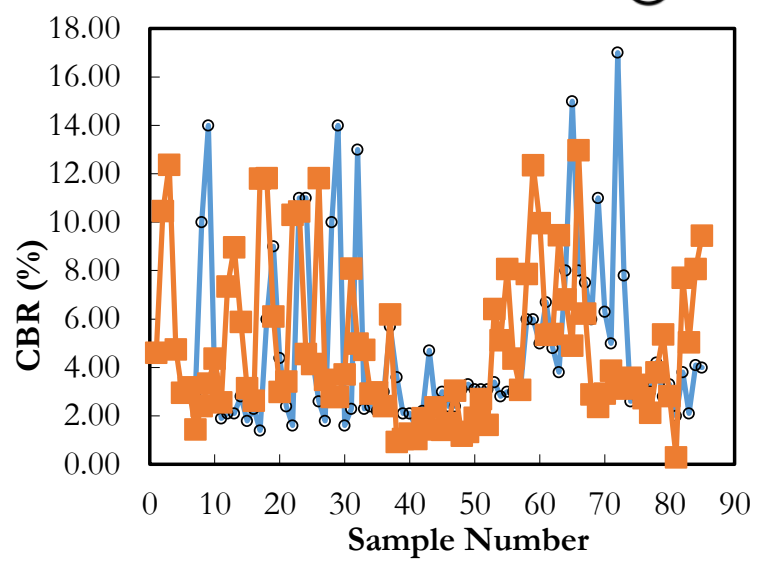

Figure 6: Comparison between predicted and computed CBR values of the soil samples.

Table 3: Summary of the developed single and multi linear regression analysis to evaluate the CBR value.

\begin{tabular}{|c|c|c|c|c|c|}
\hline Equation & $\boldsymbol{R}^{2}$ & MAE & RMSE & MSE & MAPE \\
\hline $\begin{array}{c}\text { CBR }=- \\
0.4829 \\
L L+24.018\end{array}$ & 0.7673 & 1.35 & 1.69 & 2.86 & 35.74 \\
\hline $\begin{array}{c}C B R=- \\
0.5815 \\
P L+20.497\end{array}$ & 0.5423 & 1.84 & 2.37 & 5.64 & 48.52 \\
\hline $\begin{array}{c}C B R=- \\
0.7331 P I+ \\
14.148\end{array}$ & 0.5192 & 2 & 2.4 & 5.92 & 55.4 \\
\hline $\begin{array}{c}C B R=- \\
0.8079 \text { OMC } \\
+17.338\end{array}$ & 0.5081 & 1.85 & 2.46 & 6.1 & 51.37 \\
\hline $\begin{array}{c}C B R= \\
27.094 M D D \\
-43.714\end{array}$ & 0.6489 & 1.66 & 2.1 & 4.3 & 48.88 \\
\hline $\begin{array}{c}C B R=4.32- \\
0.13662 P I- \\
0.01607 P L \\
+0.26614 \\
L L-0.13504 \\
\text { OMC }+ \\
8.563 \mathrm{MDD}\end{array}$ & 0.82 & 1.19 & 1.47 & 2.16 & 34.63 \\
\hline
\end{tabular}

\section{Conclusions}

Eighty-five natural samples of soil were taken from various selected parts of Sulaimani Governorate and utilized for soil's CBR correlation with consistency and compaction parameters. The following conclusions can be drawn based on the outcomes of current study:

- Consistency parameters (LL, PL, and PI) have a notable impact on CBR values, which yielded in CBR decrease with increases of those parameters. Significantly, the correlations are suitable for low to medium plasticity soils.

- Compaction parameters (MDD and OMC) have also significant influences on the CBR values. OMC increase decreases CBR. While, MDD increase increases CBR values.

- A slight difference exists between the laboratory CBR and multiple linear regression models' CBR obtained from correlations of CBR values with consistency and compaction parameters. 
- $\quad$ Significant coefficient of variation (adjusted $\mathrm{R}^{2}$ ) can be achieved (0.81) when CBR correlated with consistency and compaction parameters.

- From the utilized data and obtained equations, the obtain correlation equation can be used successfully to evaluate different values of soil's CBR, especially for low to medium plasticity soils.

Table 3: List of symbols/Abbreviations.

\begin{tabular}{|l|l|}
\hline Symbol & Description \\
\hline ASTM & $\begin{array}{l}\text { American Society for } \\
\text { Testing and Materials }\end{array}$ \\
\hline LL & Liquid limit (\%) \\
\hline MDD & Maximum dry density $\left(\mathrm{gm} / \mathrm{cm}^{3}\right)$ \\
\hline MAE & Mean Absolute Error \\
\hline MAPE & Mean Absolute Percentage Error \\
\hline MSE & Mean Squared Error \\
\hline OMC & Optimum moisture content $(\%)$ \\
\hline PL & Plastic limit $(\%)$ \\
\hline PI & Plasticity index (\%) \\
\hline $\mathrm{R}^{2}$ & Coefficient of determination \\
\hline RMSE & Root mean square error \\
\hline CBR & California bearing ratio $(\%)$ \\
\hline
\end{tabular}

\section{References:}

[1] S. K. Alam ., A. Mondal, and A. Shiuly, "Prediction of CBR Value of Fine Grained Soils of Bengal Basin by Genetic Expression Programming, Artificial Neural Network and Krigging Method," J Geol Soc India, vol. 95, pp. 190-196, 2020. https://doi.org/10.1007/s12594-020-1409-

[2] ASTM (2000)," Standard Practice for Classification of Soils for Engineering Purpose (Unified Soil Classification System)". ASTM Standards D 2487-00.

[3] ASTM (2010), "Standard Test Methods for Liquid Limit, Plastic Limit, and Plasticity Index of Soils". ASTM Standards D4318-10.

[4] ASTM (2012) "Laboratory Compaction Characteristics of Soil Using Modified Effort (56,000 $\mathrm{ft}-\mathrm{lbf} / \mathrm{ft} 3(2,700 \mathrm{kN}-\mathrm{m} / \mathrm{m} 3))$ ). ASTM Standards D $1557-12$.

[5] ASTM D-1883m "Standard test methods for CBR (California bearing ratio) of laboratory compacted soils". ASTM International. DOI: 10.1520/D188316, 2007.

[6] F. Attah, O. Ige, and Ogunsanwo, "Multivariate Assessment of California Bearing Ratio with Contrasted Geotechnical Properties of Soils in IlorinLokoja Highway," Engineering Geology, Essa Lwisa and Hasan Arman, IntechOpen, (April 28th 2021). DOI: 10.5772/intechopen.93523

[7] O. B. Bassey, I. C. Attah, E. E. Ambrose, and R. K. Etim, "Correlation between CBR Values and Index Properties of Soils: A Case Study of Ibiono, Oron and Onna in Akwa Ibom State," Resources and Environment, vol. 7, no. 2, pp. 94-102, 2017.

[8] V. Chandrakar and R. K.Yadav, "Study of correlation of CBR value with engineering properties and index properties of coarse grained soil," Internat. Res. Jour. Engg. Tech (IRJET), v.ol.3, no.11, pp.772778, 2016.
[9] J. Danistan and C. Vipulanandan, "Relationship between CBR Values (Un-soaked) and Undrained Shear Strength of Artificial CH Soils," Centre for Innovative Grouting Material and Technology, pp 12, 2009.

[10] I. Farias, A. William, and R. Gaby, "Prediction of California Bearing Ratio from Index Properties of Soils Using Parametric and Non-parametric Models," Geotech. Geol. Engg., vol. 36, no.6, pp.3485-3498, 2018.

[11] A. D. Gudeta and A. V. Patel, "Prediction of CBR Value from Index Properties of Different Soils: Review," International Journal of Creative Research Thoughts (IJCRT), vol. 6, no.2, pp.1190-1197, 2018.

[12] V. Katte, S. Mfoyet, M. Bertille , A. S. Wouatong, and L. Bezeng, "Correlation of California Bearing Ratio (CBR) Value with Soil Properties of Road Subgrade Soil," Geotech Geol Eng, vol.37, no.1, pp.217-234, 2019.

[13] K. S. Kumar, P. M. Nanduri, and P. N.Kumar, "Validation of Predicted California Bearing Ratio Values from Different Correlations," Amer. Jour. Engg. Res. (AJER), vol.3, no.8, pp.344-352, 2014.

[14] S. M. Lakshmi, S. Subramanian, M. P. Lalithambikhai, A. M. Vela, and \& M. Ashni, "Evaluation of Soaked and Unsoaked CBR Values of Soil Based on the Compaction Characteristics," Malaysian Journal of Civil Engineering, vol. 28, no.2, pp.172-182, 2016.

[15] M. E. Magdi and M. M. E. Zumrawi, "Prediction of Swelling Characteristics of Expansive Soils," Sudan Engineering Society Journal, vol.58, no.2, pp 55-62, 2012.

[16] Mishra A., Tegar J.P. 2019. Correlation of CBR with Index Properties of Soil of Kolar Region (Bhopal) using Regression Analysis. International Research of Engineering and technology (IRJET), 6(7):3603-3612.

[17] P. Muley and P. K. Jain, "Betterment and prediction of CBR of Stone Dust Mixed Poor Soils", Proceedings of Indian Geotechnical Conference, December 22-24, IIT Roorkee, 2013.

[18] S. A. Nugroho, A. Hendri, and R. Ningsih, "Correlation between Index Properties and California Bearing Ratio Test of Pekanbaru Soils with and without Soaked," Canadian Journal on of Environmental, Construction and Civil Engineering, vol. 3, no.1, pp 7-16, 2012.

[19] M. A. Patel, H. S. Patel, "Correlation between Physical Properties and CBR Test on Soil of Gujarat Region both in Soaked and Un-soaked Condition," International Journal of Civil Engineering and Technology, vol.3, no.2, pp 50-59, 2012.

[20] R. S. Patel and M. D. Desai, "CBR Predicted by Index Properties for Alluvial Soils of South Gujarat," Indian Geotechnical Conference, December 16-18, pp 79-82, 2010.

[21] M. Prashanth, N. Rao, and N. Kommu, "Prediction of Soaked CBR Value with Index Properties of Black Cotton Soils of Sangareddy Region," i-manager's Journal on Civil Engineering., vol.7, no.1, pp.8, 2017.

[22] G. V. Ramasubbarao and S. G. Siva, "Predicting Soaked CBR Value of Fine-Grained Soils Using 
Index and Compaction Characteristics," Jordan Journal of Civil Engineering, vol. 7, no. 3, pp 354360, 2013.

[23] S. Roy, "Assessment of Soaked California Bearing Ratio Value Using Geotechnical Properties of Soils," Resources and Environmen, vol.6, no. 4, pp. 80-87, 2016.

[24] T. K. Roy, B. C. Chattopadhyay, and S. K. Roy, "Prediction of CBR from Compaction Characteristics of Cohesive Soil," Highway Research Journal, JulyDec, pp 77-88, 2009.

[25] P. P. Saklecha, R. S. Kedar, and P. K. Saklecha, "Correlation of CBR with mechanical properties of foundation soil," Proc. of Indian Geotechnical Conference December 22-24, Roorkee, pp. 1-8, 2013. [26] N. B. Shirur, S. G. Hiremath, " Establishing Relationship between CBR Value and Physical Properties of Soil," IOSR Journal of Mechanical and Civil Engineering, vol. 11, no.1, pp 26-30, 2014.

[27] D. Singh, "Moisture and Compaction Based Statistical Model for Estimating CBR of FineGrained Subgrade Soil," International Journal of Earth Sciences and Engineering ISSN 0974-5904, vol. 4, no. 6, pp 100-103, 2011.

[28] D. K. Talukdar, "A Study of Correlation Between California Bearing Ratio (CBR) Value with Other Properties of Soil," International Journal of Emerging Technology and Advanced Engineering, vol. 4, no.1, pp 559-562, 2014.

[29] D. K. Talukdar, D.K., "A Study of correlation between California bearing ratio (CBR) value with other properties of soil," IJETAE, vol.4, no.1, pp. 559-562, 2014.

[30] S. T. Torgano, M. S. Ali, E. T. Yenealem, and A. T. Tumato, "Correlation between CBR Values and Index Properties of Subgrade Soils: In The Case Of Boditi Town," IJARIIE, vol. 6, no.3, pp.1167-1182, 2020.

[31] G. Priya, K. S. Arya, E. M. Manjummekudiyil, A. Unni, and V. S. Menon, "Prediction of CBR Value from Index Properties of Soil," International Research of Engineering and technology (IRJET), vol. 6, no. 4, pp. 4029-4033, 2019.

[32] C. Venkatasubramanian and G. Dhinakaran, "ANN Model for Predicting CBR from Index Properties of Soils," International Journal of Civil and Structural Engineering, Integrated Publishing Association (IPA), vol.2, no.2, pp 605-611, 2011.

[33] B. Yıldirım and O. Gunaydın, "Estimation of California Bearing Ratio by Using Soft Computing Systems," Expert Systems with Applications, vol. 38, pp 6381- 6391, 2011. 